\title{
Sistema multiagente aplicado ao ambiente Moodle para facilitar a colaboração entre os estudantes
}

\author{
Jhony Luiz de Almeida1, Benjamin Grando Moreira² \\ ${ }^{1}$ Universidade do Vale do Itajaí (UNIVALI) - Itajaí - SC - Brasil \\ ${ }^{2}$ Universidade Federal de Santa Catarina (UFSC) - Joinville, SC - Brasil \\ w.jhony@hotmail.com, benjamin.grando@ufsc.br
}

\begin{abstract}
This paper present a multi-agent system to the Moodle environment to increase collaboration between students. The system has interface agents that act as personal assistants for students, identifying the contents that the student have difficulty and suggesting educational resources and colleagues that are able to assist. The agents were developed using the JADE framework, and Moodle block and the communication between agents and the block was performed by WSIG.
\end{abstract}

Resumo. Esse trabalho apresenta um sistema multiagente integrado ao ambiente Moodle para ampliar a colaboração entre alunos no aprendizado. $O$ sistema possui agentes de interface que desempenham o papel de assistentes pessoais dos alunos, identificando os conteúdos em que possuem dificuldade e sugerindo recursos educacionais e colegas capazes de lhe ajudar por chat. Os agentes foram desenvolvidos utilizando o framework JADE, e o componente de bloco do Moodle e a comunicação entre bloco e os agentes foi realizada através da extensão WSIG do JADE.

\section{Introdução}

Apesar de ser uma prática existente desde o século XV, a Educação a Distância $(\mathrm{EaD})$ carregou por um bom tempo consigo o estigma de estepe do ensino, ou seja, uma forma de suprir lacunas das modalidades tradicionais [Alves 1998]. [Lévy 1996] cita que os meios de comunicação utilizados não permitiam a mesma efetividade e interatividade de encontros presenciais.

A situação mudou com a ascensão das tecnologias da informação, sobretudo a Internet que, para [Azevedo 1999], trouxe suporte de diversas mídias e à instantaneidade na troca de informações e fez a $\mathrm{EaD}$ ganhar uma nova perspectiva, dando suporte á possibilidades de interação entre participantes. Entre os instrumentos utilizados na $\mathrm{EaD}$, destacam-se os ambientes virtuais de aprendizagem (AVA).

A utilização de um AVA gera oportunidades para iniciativas que busquem aprimorar o processo de aprendizagem dos alunos, foi desenvolvido um sistema multiagente para auxiliar de forma personalizada os alunos. O sistema, nomeado Erudio, foi desenvolvido com o framework para sistemas multiagentes JADE, e atua como um assistente pessoal do aluno, identificando os conteúdos em que ele possui dificuldade e apresentando sugestões (material de consulta ou colegas de classe). As sugestões de ajuda são apresentadas por meio de uma interface integrada ao ambiente virtual, implementada como um componente da plataforma Moodle. 


\section{Fundamentação Teórica}

A Fundamentação Teórica deste trabalho sintetiza o conceito de sistemas multiagentes e o framework JADE utilizados no sistema proposto. Também são apresentados trabalhos similares e a contribuição deles para o projeto.

\subsection{Agentes e Sistema Multiagentes}

De forma sintetizada, agente é um sistema computacional capaz de efetuar ações de forma autônoma sobre o ambiente em que atua, visando alcançar seus objetivos de projeto [Wooldridge 2002].

Sistema Multiagente (SMA) é um sistema formado por um conjunto de agentes que interagem entre si por meio da troca de mensagens. Em um sistema deste tipo, o alcance dos objetivos globais é dependente da cooperação entre os agentes, já que cada um é autônomo e não pode ser forçado por outro a realizar tarefas ou ter seu estado interno alterado diretamente [Wooldridge 2002].

\subsection{Framework JADE}

JADE é um framework desenvolvido na linguagem de programação Java cujo objetivo é simplificar a implementação de sistemas multiagente, garantindo total cumprimento com as especificações da FIPA (Foundation for Intelligent Physical Agents - Fundação para agentes físicos inteligentes) [JADE 2014].

O escopo dos padrões FIPA engloba a comunicação entre os componentes de um SMA, o ciclo de vida dos agentes e os serviços básicos necessários, abstraindo a estrutura interna dos agentes. A plataforma de agentes do JADE oferece todos os componentes obrigatórios da FIPA, como serviço de nomes, serviço de páginas amarelas, protocolos de interação e transporte de mensagens. Toda comunicação entre os agentes é realizada através de mensagens na linguagem FIPA-ACL. Os agentes do JADE abitam em containers e cada agente é executado como uma thread, porém o framework suporta que cada agente realize suas tarefas de forma paralela, através do escalonamento de comportamentos (behaviours) [JADE 2014].

\subsection{Trabalhos similares}

Em [Ribeiro, Reategui e Boff 2007] foi introduzido um agente pedagógico no ambiente Moodle, com o propósito de adicionar um componente sócio-afetivo à interface do sistema e promover a interação entre os alunos. O agente recomenda tutores para alunos que aparentem estar com dificuldades em uma atividade, abrindo um canal de comunicação entre os alunos, o qual foi criado por meio de modificações no fórum nativo do Moodle. Um dos parâmetros usados para sugerir que um aluno está com dificuldades foi o número de acessos a uma atividade sem solucioná-la.

O trabalho de [Lin et al. 2010] desenvolveu agentes de monitoramento para o módulo de fórum, visando automatizar a análise da participação dos alunos nesta modalidade de atividade. $\mathrm{O}$ objetivo dos agentes foi em determinar: número de postagens de cada aluno; procurar por alunos que não participaram no fórum; identificar discordâncias entre alunos; inserir novas postagens no fórum; e enviar e-mail ao tutor do curso contendo as informações colhidas. 
Com relação aos trabalhos similares, foi adotada a ideia de recomendação de tutores apresentada no primeiro trabalho, por ser uma forma de incentivar o aprendizado cooperativo apoiado pelo sócio-construtivismo, porém foi implementado um canal de comunicação próprio de forma a evitar modificações em componentes nativos do Moodle. O método de avaliação de desempenho dos alunos em disciplinas utilizado no sistema desenvolvido é mais similar ao apresentado no segundo trabalho, entretanto, a atividade usada como referência é o questionário associado ao uso de tags.

\section{Projeto}

O sistema multiagente desenvolvido teve como objetivo fornecer um assistente pessoal aos alunos que utilizam o Moodle e possui as seguintes funcionalidades: (1) reconhecer os conteúdos em que o aluno possui dificuldade; (2) pesquisar e sugerir materiais de aprendizagem relacionados a um determinado conteúdo; e (3) sugerir outros usuários conectados que possam prestar auxílio em um determinado conteúdo.

Estruturalmente, o sistema Erudio foi segmentado em três camadas, onde a primeira é o SMA propriamente dito, sendo responsável pelo processamento das informações extraídas da base do ambiente. A segunda é composta por um componente Moodle, o qual possui como função primária a apresentação das informações aos usuários. Por último, a terceira camada tem exclusivamente a responsabilidade de prover um canal de comunicação entre as outras. A seguir, as subseções apresentam detalhes das camadas da arquitetura do sistema.

\subsection{Camada de processamento}

Foram especificados e desenvolvidos cinco tipos de agente, cada um possuindo responsabilidades distintas. O principal tipo de agente do Erudio é o assistente. Trata-se de um agente de interface responsável por atender exclusivamente um aluno conectado ao AVA, comunicando-se com ele por intermédio de uma interface gráfica.

O método utilizado para definir o desempenho do aluno em conteúdos é a análise das respostas nos questionários. No Moodle, cada questão pode estar associada à marcadores (tags) que representam os conteúdos abordados. O assistente consulta as questões respondidas pelo aluno e as tags de conteúdo de cada uma, contabilizando os erros e acertos.

Um desempenho inferior ao indicador BOM, o qual foi definido arbitrariamente como 0.8 (oitenta por cento do questionário), faz o agente assistente apresentar ao aluno a opção de procurar alguém para ajudá-lo e uma lista de links para materiais de estudo.

Enquanto os links apenas levam o aluno diretamente ao material, a opção de busca por ajuda enviará uma ordem ao agente assistente, que o fará enviar um pedido de ajuda aos assistentes de outros alunos. Cada agente que recebe o pedido analisa se o seu aluno está apto a atendê-lo, e em caso positivo, exibe para ele o pedido e as opções de ajudar ou ignorar. Finalmente, caso o pedido de ajuda seja aceito, os agentes do solicitante e do colaborador abrem uma janela de chat aos seus alunos.

Os critérios para um assistente decidir se o seu aluno está apto ou não a atender um pedido de ajuda são o seu desempenho no conteúdo solicitado, que possui peso de relevância de $70 \%$, e a porcentagem de pedidos aceitos anteriormente, com peso de $30 \%$. A porcentagem de pedidos aceitos foi considerada já que alguns alunos podem 
destacar-se em prestar ajuda aos colegas, enquanto outros podem não ter interesse em atuar colaborativamente, mesmo tendo bom desempenho no conteúdo.

Os demais tipos de assistente do sistema possuem funções de gerência ou auxilio aos assistentes. O buscador e o classificador possuem as respectivas funções de buscar materiais de estudo no ambiente e atribuir automaticamente tags às questões. $\mathrm{O}$ buscador é capaz de buscar por palavras-chave na descrição dos materiais existentes no ambiente, e é solicitado diretamente pelos assistentes quando estes desejam sugerir materiais aos seus alunos (como os relacionados na parte central da Figura 1).

$\mathrm{Na}$ parte da gerência, existem os agentes controlador e gerente de curso. O controlador é responsável por criar instâncias de gerentes para cada curso e o gerente, por sua vez, tem como função monitorar os alunos de seu curso que se conectam e desconectam, gerenciando assim a criação e destruição de seus agentes assistentes.

\subsection{Camada de apresentação}

A interface gráfica do assistente do aluno foi desenvolvida como um componente do Moodle, mais especificamente um bloco. O bloco criado possui como elementos principais a representação visual do assistente, sua fala ao aluno, e possivelmente, links para materiais e botões de comando. A imagem do assistente possui variações de humor condizentes com as falas, podendo expressar desde felicidade até preocupação, conforme observado na Figura 1. Os botões de comando, como o que permite ao aluno buscar ajuda de outro colega, diferem dos links por, ao invés de encaminhar o aluno a uma página ou arquivo, envia uma ordem diretamente ao agente assistente, por meio da camada de comunicação do bloco com o SMA.

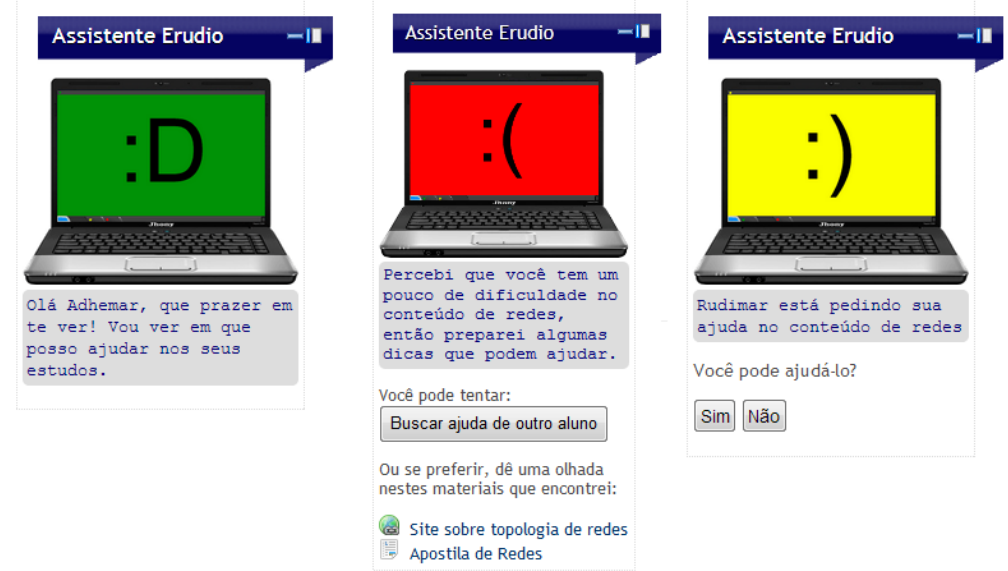

Figura 1. Exemplos de telas do bloco Assistente Erudio

\subsection{Camada de comunicação}

Para realizar a comunicação entre o agente assistente do aluno (feito no JADE) e a camada de apresentação (feita no Moodle) foi utilizada uma extensão do JADE, denominada WSIG, que é capaz de expor serviços na forma de web services SOAP.

O WSIG é uma aplicação composta por dois elementos: (1) Servlet; e (2) agente JADE. O Servlet WSIG é responsável por interceptar as requisição SOAP e converter seu conteúdo em um objeto Java que representa uma ação. O agente WSIG recebe do Servlet o objeto e o encaminha para o agente capaz de cumprir a ação correspondente, 
obtendo o resultado da execução e repassando-o de volta ao Servlet. Uma vez que o Servlet recebe um resultado de execução, ele o converte em uma resposta SOAP e envia ao cliente que fez a requisição, encerrando o ciclo [JADE BOARD 2013].

\section{Conclusões}

A ideia central que motivou o desenvolvimento do sistema computacional apresentado foi incorporar ao Moodle um assistente virtual que auxiliasse os alunos nos conteúdos em que apresentassem dificuldades.

A escolha de implementar a interface do assistente como um bloco do Moodle tornou possível que o sistema Erudio seja incorporado a qualquer ambiente baseado nesta plataforma. Além do próprio sistema multiagente, o único requisito adicional é a instalação da extensão WSIG do JADE, que provê os web services responsáveis por comunicar os agentes à camada de apresentação. O WSIG necessita apenas de um container de Servlets Java. Embora o JADE e o WSIG tenham sido executados na mesma máquina, as três camadas do sistema podem estar localizadas em máquinas distintas, bastando alterar seus arquivos de configuração.

Para determinar que um aluno tem dificuldade em algum conteúdo, o agente assistente do aluno apenas considera a taxa de erros de um questionário. Outras estratégias também podem ser elaboradas, principalmente se fosse possível relacionar conteúdos, por exemplo, identificando um conteúdo como pré-requisito para outro.

Por fim, esse trabalho mostrou uma alternativa de colaboração entre alunos para auxiliar no processo de aprendizagem, mas destaca-se também a parte técnica com a aplicação de sistemas multiagentes no ambiente Moodle e permitindo a comunicação dos agentes diretamente com um componente do Moodle.

\section{Referências}

Alves, J. R. M. (1998) "Educação a Distância e as Novas Tecnologias de Informação e Aprendizagem", http//www.engenheiro2001.org.br/programas/980201a1.htm, 06 mar. 2012.

Azevedo, W. (1999) "Panorama atual da Educação a Distância no Brasil", http//www.escolanet.com.br/sala_leitura/txt_integral.html, 06 mar. 2012.

JADE (2014) “Jade Framework", http://jade.tilab.com, 21 abr. 2014.

JADE BOARD (2013) "Jade Web Services Integration Gateway (WSIG) Guide", http:/jade.tilab.com/doc/tutorials/WSIG_Guide.pdf, 08 ago. 2014.

Lévy, P. (1996) “O que é o virtual?” São Paulo, Editora 34.

Lin, F., et al. (2010) "Integrating JADE agents into MOODLE", http $/ /$ auspace.athabascau.ca/hand le/2149/2605, 09 abr. 2014.

Ribeiro, J. P. A.; Reategui, E.; Boff, E. (2007) "Integrando um agente pedagógico para recomendação de tutores a um sistema de gerência de cursos", In: IX Ciclo de Palestras sobre Novas Tecnologias na Educação, http//www.cinted.ufrgs.br/ciclo9/artigos/7dJoaoPedro.pdf, 09 abr. 2014.

Wooldridge, Michael J. (2002) "An introduction to multiagent systems", New York, J. Wiley \& Sons. 